\title{
CRLF2 Positive
}

National Cancer Institute

\section{Source}

National Cancer Institute. CRLF2 Positive. NCI Thesaurus. Code C131217.

An indication that CRLF2 expression has been detected in a sample. 